\section{Signet ring cell carcinoma mimicking ileal Crohn's disease}

\author{
Serkan Dogan, ${ }^{1}$ Mehmet Celikbilek, ${ }^{2}$ \\ Eray Eroglu, ${ }^{3}$ Ahmet Yagbasan, ${ }^{1}$ \\ Gulten Can Sezgin, ${ }^{1}$ Sebnem Gursoy, ${ }^{1}$ \\ Kemal Deniz ${ }^{4}$ \\ 1 Department of Gastroenterology and \\ Hepatology, Erciyes University, Medical \\ School, Kayseri; ${ }^{2}$ Department of \\ Gastroenterology and Hepatology, Bozok \\ University, Medical School, Yozgat; \\ ${ }^{3}$ Department of Internal Medicine, \\ Erciyes University, Medical School, \\ Kayseri; ${ }^{4}$ Deparment of Pathology, \\ Erciyes University, Medical School, \\ Kayseri, Turkey
}

\begin{abstract}
Signet ring cell carcinoma is a subtype of adenocarcinoma and mainly originated from stomach. Terminal ileum involvement is uncommon and only 2 cases have been reported in the literature. We represent a case of signet ring cell carcinoma of the terminal ileum showing gross features mimicking Crohn's disease in a patient with ankylosing spondylitis.
\end{abstract}

\section{Introduction}

Signet ring cell carcinoma (SRCC) can develop in numerous organs, but it generally emerges in the gastrointestinal system, predominantly affects the stomach. But it can also develop in the breast, prostate, urinary bladder, lung or may arise in other sites of the body. To our knowledge, only two cases with ileal involvement have been reported in the literature. ${ }^{1,2}$ We present a case of SRCC mimicking ileal Crohn's disease in a patient with ankylosing spondylitis.

\section{Case Report}

A 69-year-old man was admitted to the hospital because of mild, episodic, and crampy abdominal pain, nausea, and vomiting for 2 months of duration. He had a history of ankylosing spondylitis since the age of 45 years. He was taking leflunamid associated with ankylosing spondylitis (AS) for two years. Abdominal examination revealed mild distention, tympany, and voluntary guarding but no rebound or overt signs of peritonitis. Plain-film radiographs of the abdomen revealed air-fluid levels. Ultrasonography of the abdomen showed a thickened terminal ileum wall. Computed tomography of the abdomen with intravenous contrast material revealed substantial luminal narrowing, most likely from thickening of the ileal wall (Figure 1). The passage was not completely obstructed, and we were able to pass the endoscope into the ileum, which appeared an edematous and erythematous ileal mucosa with linear ulcers mimicking Crohn's disease. Upper endoscopy showed mild gastritis and normal-appearing duodenal mucosa. Histopathological analysis of ileal-biopsy specimens obtained from the sites of inflammation showed signet ring cells infiltrating the lamina propria of the ileum.

The patient underwent operation. During laparotomy, an edema and wall thickening in the ileum was observed and right hemicolectomy was performed. The surgically resected specimen measured $55 \mathrm{~cm}$ in length. The wall of the small bowel was thickened in a $15 \mathrm{~cm}$ segment of the terminal ileum (Figure 2). Light microscopic examination revealed signet ring cells infiltrating the ileal wall invading the serosal surface (Figure 3). Superficial ulceration of the ileal mucosa was observed. However, no granuloma and transmural inflammation were observed. Postoperative histopathological examination showed that the patient had T4N2M, stage IIIB ileal cancer. The patient received adjuvant chemotherapy that include 5-FU, Folinic acid and oxaliplatin combination. The patient is free of disease for 6 months of follow-up.

\section{Discussion}

Signet ring cell carcinoma can arise in many organs, including the stomach, gallbladder, breast, lung, pancreas, genitourinary tract, esophagus and large intestine but it occurs most frequently in the stomach. Signet-ring cell histology has been found in approximately one fourth of gastric cancers, whereas other organ tumors (e.g., breast and colon cancers) with signet-ring cell morphology found to have a very low incidence $(<1 \%)^{3,4}$

SRCC originated from the ileum is extremely rare. Only two cases have been described in the medical literature. One of these cases, had developed after a longstanding inflammation of Crohn's disease. ${ }^{1}$ The other case is primary signet-ring cell carcinoma of the ileum without any underlying cause and this case presented with nausea and abdominal distension similar to our patient. ${ }^{2}$ The patient underwent surgery with a diagnosis of ileal tumor one year after the presentation. Nevertheless, they could not perform a curative operation due to the metastasis. The patient died 5 months after the operation despite anticancer chemotherapy. The curative treatment requires surgery but unfor-
Correspondence: Serkan Dogan, Erciyes Üniversitesi Tıp Fakültesi Hastanesi Gastroenteroloji Bilim Dalı, Talas / Kayseri, Turkey.

Tel. +90.532 .4283260 - Fax: +90.352 .4375273 .

E-mail: serkanmd2004@yahoo.com

Key words: signet ring cell carcinoma, terminal ileum, Crohn's disease, ankylosing spondylitis.

Conflict of interests: the authors declare no potential conflict of interests.

Received for publication: 29 September 2012.

Revision received: 17 December 2012.

Accepted for publication: 7 January 2013.

This work is licensed under a Creative Commons Attribution NonCommercial 3.0 License (CC BYNC 3.0).

(C) Copyright Serkan Dogan et al., 2013

Licensee PAGEPress, Italy

Gastroenterology Insights 2013; 5:e2

doi:10.4081/gi.2013.e2

tunately $50-70 \%$ patients are found to be metastatic at the time of surgery. ${ }^{2}$ In our patient curative surgery has been performed without any metastatic lesion and clinical condition after the follow up was excellent.

Regional involvement of ileum with thickening of its wall can be seen in a variety of disorders; such as infectious colitis, ${ }^{5}$ ischemic colitis ${ }^{6}$ Crohn's disease, ${ }^{7}$ ulcerative colitis, ${ }^{8}$ systemic vasculitis, especially Behcet's disease, ${ }^{9}$ and malignant tumors, primarily lymphoma. ${ }^{10}$ Although whole gastrointestinal tract can be affected by Crohn's disease, most frequent involvement is seen in the terminal ileum. It produces transmural inflammation characterized by edema and infiltration with lymphocytes and plasma cells in all layers of the bowel wall. Although the patient's clinical and radiological presentations were suggestive of Crohn's disease with history of ankylosing spondylitis, ${ }^{11}$ absence of fistula formation with a relatively short history of presentation for such an advanced obstruction causing etiology had aroused suspicions in the diagnosis. Crohn's disease was ruled out with the analysis of histopathological specimen.

The relationship between Crohn' disease and AS has been recognized for many years. They share some common clinical, genetic, and microbiological findings. Crohn' disease can be develops in patients primarily diagnosed with AS. Nevertheles, cancerous condition also can be accompanied such as in this case. The risks of multiple myeloma and monoclonal gammopathy of uncertain significance are significantly elevated in those with AS. ${ }^{12}$ But, the evidence does not support an increased rate of gastrointestinal malignancy in AS..$^{13}$ 


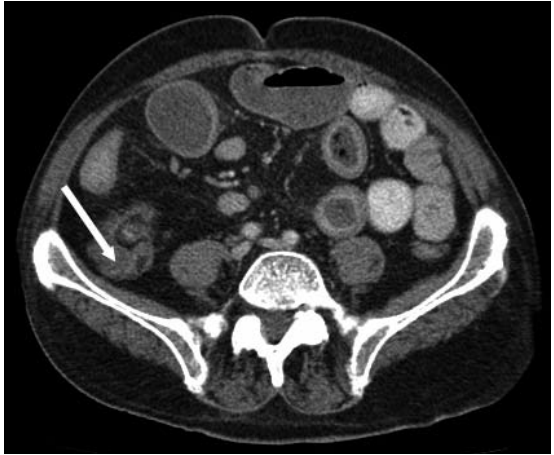

Figure 1. Computed tomography scan of the abdomen, demonstrating a thickened wall in the distal small bowel (arrow).

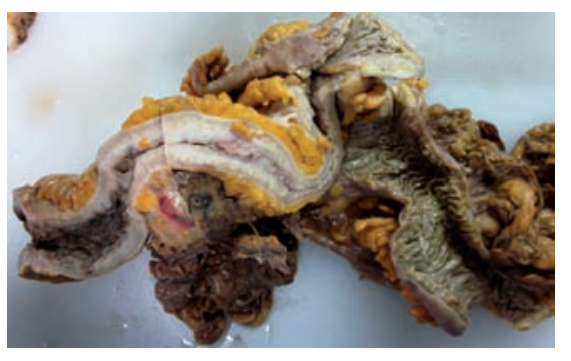

Figure 2. Gross specimen of the terminal ileum showing thickened intestinal wall.

\section{Conclusions}

In conclusion, possible existence of SRCC should be kept in mind in ileal lesions mimicking Crohn's disease along with ankylosing spondylitis.

\section{References}

1. Kim JS, Cheung DY, Park SH. A case of small intestinal signet ring cell carcinoma in Crohn's disease. Korean J Gastroenterol 2007;50:51-5.

2. Iizawa H, Ikeda E, Sato T, Ohta Y. Signetring cell carcinoma of the ileum: report of a case and review of the Japanese literature. Surg Today 1998;28:1168-71.

3. Theuer CP, Nastanski F, Brewster WR, et



Figure 3. Light microscopy showing neoplastic infiltration of the ileal wall by signet ring cells (arrows); Hematoxylin and Eosin, $\times 40$.

al. Signet-ring cell histology is associated with unique clinical features but does not affect gastric cancer survival. Am Surg 1999;65:915-21.

4. Yokota T, Kunii Y, Teshima S, et al. Signet ring cell carcinoma of the stomach: a clinicopathological comparison with the other histological types. Tohoku J Exp Med 1998;186:121-30.

5. Klempner MS, Talbot EA, Lee SI. Case records of the Massachusetts General Hospital. Case 25-2010. A 24-year-old woman with abdominal pain and shock. N Engl J Med 2010;363:766-77.

6. Hobolth L, Bendtsen F. [Cocaine-triggered ischaemic enteritis]. Ugeskr Laeger 2009;171:2748-50. [Article in Danish].

7. Headstrom PD, Rulyak SJ, Lee SD. Prevalence of and risk factors for vitamin $\mathrm{B}(12)$ deficiency in patients with Crohn's disease. Inflamm Bowel Dis 2008;14:217.

8. Goldstein N, Dulai M. Contemporary morphologic definition of backwash ileitis in ulcerative colitis and features that distinguish it from Crohn disease. Am J Clin Pathol 2006;126:365-76.

9. Chung SY, Ha HK, Kim JH. Radiologic findings of Behçet syndrome involving the gastrointestinal tract. Radiographics 2001;21: 911-24.

10. Koh DH, Lee KN A case of natural killer like $\mathrm{T}$ cell lymphoma misdiagnosed as Behcet's Enteritis of the terminal ileum. Korean J Gastroenterol 2011;57:365-9.

11. De Keyser F, Elewaut D, De Vos M. Bowel inflammation and the spondyloarthropathies. Rheum Dis Clin North Am 1998; 24:785.

12. Kumar S, Gnanapandithan K, Sharma A, et al. Development of multiple myeloma in a case of longstanding ankylosing spondylitis: more than a coincidence? Int J Rheum Dis 2011;14:e12-3.

13. Hemminki K, Liu $X$, Ji J, et al. Autoimmune disease and subsequent digestive tract cancer by histology. Ann Oncol 2012;23:927-33. 